\title{
DNA topoisomerase II $\alpha$ and Ki67 are prognostic factors in patients with hepatocellular carcinoma
}

\author{
YI CAO*, RUISHENG KE*, SHAOHU WANG, XU ZHU, JIANWEI CHEN, CHAO HUANG, YI JIANG and LIZHI LV \\ Department of Hepatobiliary Surgery, Fuzhou General Hospital, Fuzhou, Fujian 350025, P.R. China
}

Received February 20, 2016; Accepted February 7, 2017

DOI: $10.3892 / 01.2017 .5999$

\begin{abstract}
The present study was designed to determine the significance of DNA topoisomerase IIa (TopoII $\alpha$ ) and Ki67 in hepatocellular carcinoma cells (HCCs). The present study included 353 patients with HCC. The association of clinicopathological data with the expression of TopoII $\alpha$ and Ki67 by immunohistochemistry was analyzed by $\chi^{2}$ test. Cox multivariate proportional hazards regression analysis and Kaplan-Meier analysis were performed with all the variables to derive risk estimates associated with overall survival (OS)/recurrence-free survival (RFS) and to control for confounders. TopoII $\alpha$ and $\mathrm{Ki} 67$ were detected in the nuclei of the tumor cells. With TopoII $\alpha, 35.7 \%$ of cells exhibited high expression, which was associated with tumor-node-metastasis stage, tumor size and $\alpha$-fetoprotein level. With Ki67, 37.1\% of cells exhibited high expression, which was associated with tumor-node-metastasis stage, tumor size and $\alpha$-fetoprotein level. Correlation was identified between the expression level of TopoII $\alpha$ and $\mathrm{Ki} 67$ in HCCs ( $\mathrm{r}=0.444)$. Multivariate analysis revealed that high TopoII $\alpha$ expression is a prognostic indicator for RFS [hazard ratio (HR), 2.002; 95\% confidence interval (CI), 1.429-2.806] and OS (HR, 2.749; 95\% CI, 1.919-3.939), and high $\mathrm{Ki} 67$ expression is a prognostic indicator for OS (HR, 1.816; 95\% CI, 1.273-2.589). The TopoII $\alpha$-low group had a significantly increased RFS rate (55.6 vs. $31.7 \%$ ) and OS rate (66.5 vs. $23.8 \%$ ) compared with the TopoII $\alpha$-high group. The OS rate was increased in the Ki67-low group compared with the Ki67-high group (67.0 vs. 26.5\%). Expression of TopoII $\alpha$ and $\mathrm{Ki} 67$ are independent prognostic factors for survival in HCCs. TopoII $\alpha$ was positively associated with Ki67 expression.
\end{abstract}

Correspondence to: Professor Lizhi Lv, Department of Hepatobiliary Surgery, Fuzhou General Hospital, 156 North Xi-er Huan Road, Fuzhou, Fujian 350025, P.R. China

E-mail: tooyizhi@163.com

*Contributed equally

Key words: hepatocellular carcinoma, prognosis, DNA topoisomerase II $\alpha, \mathrm{Ki} 67$

\section{Introduction}

Hepatocellular carcinoma (HCC) is the third most common cause of cancer-associated mortality globally, and it is more prevalent in men compared with women (1). According to one estimation, 745,500 mortalities occurred among the 782,500 new liver tumor cases worldwide during 2012 (2). Currently, surgical resection is the optimal treatment strategy to offer long-term survival outcomes for patients with HCC. However, the clinical behavior of HCC may vary. In certain patients, the disease runs an aggressive course with a survival of several months, whereas other patients may have a relatively slow clinical evolution and survive for >5-10 years following diagnosis. An improved understanding of the pathogenesis and identification of novel biomarkers for HCC may provide physicians treating this disease with additional therapeutic options. Although it has been proposed that several molecular markers, including $\alpha$-fetoprotein (AFP), may be associated with the prognosis of HCC, their clinical applications are limited (3-5). Therefore, previous studies have focused on seeking new biomarkers for the prognosis and therapeutic targeting of HCC (6-8).

The proliferation status of tumor cells is an important parameter that reflects the biological characteristics of the tumor, and affects the prognosis and efficiency of treatment of the tumor directly. DNA topoisomerases are enzymes essential for DNA replication, transcription and recombination, as well as for chromosome compaction and segregation (9). Several families and subfamilies of the two types (I and II) of DNA topoisomerases have been described (9). There are two isoforms of topoisomerase II in humans, $\alpha$ and $\beta$, coded on chromosomes $17 \mathrm{q} 21-22$ and $3 \mathrm{p} 24$, respectively $(10,11)$. TopolI $\alpha$ is essential for the survival of actively growing cells. Enzyme concentrations are upregulated markedly during periods of cell proliferation, and TopoII $\alpha$ levels increase over the cell cycle and have an increased peak in the $\mathrm{G} 2 / \mathrm{M}$ phase (9). Considering the previously mentioned role of TopolI $\alpha$ in cell division and its increased expression in the $\mathrm{G} 2 / \mathrm{M}$ phase of the cell cycle, immunohistochemical staining for TopolI $\alpha$ may be useful in the determination of cell proliferation, and eventually malignant transformation (9-11). Previous studies have considered TopoII $\alpha$ as a prognostic factor in patients with esophageal squamous cell carcinomas, breast cancer, clear cell renal cell carcinoma and nasopharyngeal carcinoma (12-15). 
One of the established proliferation markers is Ki67 protein, which may be detected within the cell nucleus. As $\mathrm{Ki} 67$ protein is present during all active phases of the cell cycle (G1, S, G2 and mitosis) but is absent in the resting cell (G0), it is an effective marker for determining the growth fraction of a given cell population (16). In a multi-ethnic sample of patients with breast cancer, Ki67 was revealed to be a significant independent prognostic marker (17).

Various studies have been performed with TopoII $\alpha$ or Ki67 individually to investigate their role as prognostic markers for the survival of patients with HCC. However, thus far, whether TopoII $\alpha$ or Ki67 affect the long-term survival of patients with HCC is controversial. The present study investigated TopoII $\alpha$ and $\mathrm{Ki} 67$ expression and evaluated their utility in predicting the outcomes of patients with HCC.

\section{Materials and methods}

Patients and tumor samples. HCC tumor samples (353 in total) were obtained from patients who underwent hepatic surgical resection without preoperative chemotherapy at the Fuzhou General Hospital (Fujian, China) between February 2003 and October 2012. Using the International Union Against Cancer tumor-node-metastasis (TNM) classification system (18) to classify resected specimens, 251 cases at stage I/II and 102 cases at stage IIIa were identified. Histological grades were classified as well/moderately-differentiated $(n=329)$ and poorly-differentiated $(n=24)$. All the patients enrolled in the present study conformed to the following criteria: No tumor thrombus in the portal vein; only one tumor lesion; 0-1 Eastern Cooperative Oncology Group score prior to surgery (liver function grade Child-Pugh class A; no distant metastasis, ascites or hepatic encephalopathy); no cancer treatment prior to surgery, and pathology confirmed as primary HCC following surgery; complete clinical records and follow-up information available; no history of other tumors; radical resection. Radical resection was defined as follows: All lesions were resected and confirmed by intraoperative ultrasonography; pathology proved to be negative; the tumor thrombus following two branches were able to be resected. Exclusion criteria were: Insufficient liver tissue on the biopsy specimen for extra analysis or insufficient clinical data regarding patient outcome; and without history of hepatitis $B$ virus infection.

The clinical data analysis staff members were blinded to the TopoII $\alpha$ and Ki67 expression levels in the liver cancer samples, and the laboratory and analysis staff members did not view the clinical data. The present study protocol was approved by the Ethical Committees of Fuzhou General Hospital (Fuzhou, China) and informed consent was obtained from all patients.

Follow-up subsequent surgery. Patients who underwent hepatectomy between February 2003 and October 2012 were subjected to close clinical observation, including abdominal computed tomography imaging, AFP level and liver function tests at 2-4-month intervals. The follow-up end date was October 1st 2014, and the median follow-up time was 34 (range, 2-122) months. The follow-up was conducted via telephone or questionnaire as supplementary methods.
Immunohistochemical (IHC) analysis. IHC methods previously described by Schmilovitz-Weiss et al (19), for Ki67 assay were used to analyze the expression of Ki67 using anti-Ki67 antibody (Maixin Biotechnology Co., Ltd., Fujian, China; clone no., MID-1; dilution, 1:130) to replace the antibody. The same method was used to analyze the expression of DNA TopoII $\alpha$, using anti-DNA TopoII $\alpha$ antibody (Maixin Biotechnology Co., Ltd; clone no., 3F6; dilution, 1:150) to replace the antibody.

Evaluation of IHC staining. The 353 stained tissue sections (4- $\mu \mathrm{m}$ thick) were evaluated on separate occasions by two pathologists with no previous knowledge of any patient information. Semi-quantitative IHC detection was used to determine TopoII $\alpha$ protein level with a 4-point scale, as follows: No positive cells, $0 ;<25 \%$ positive cells, $1 ; 25-50 \%$ positive cells, $2 ; \geq 50 \%$ positive cells, 3 . HCC tissue samples graded 0 or 1 were judged as low TopoII $\alpha$ expression, whereas those graded 2 or 3 were regarded as high TopoII $\alpha$ expression.

As Ki67 expression was mostly homogenous, it was scored as a percentage of positively-stained cells, based on the following standards: (-), cancer cells unstained or stained $<10 \%$ (cancer cells stained $\geq 10 \%$ were identified as positive); $(+)$, cancer cells stained 10-25\%; (++), cancer cells stained 26-50\%; (+++), cancer cells stained 51-75\%; (++++) cancer cells stained $>75 \%$. HCC tissue samples with (-) or (+) Ki67 expression levels were judged as low Ki67 expression; samples with $(++),(+++)$ or $(++++) \mathrm{Ki} 67$ expression were regarded as having high $\mathrm{Ki} 67$ expression.

Statistical analysis. Analyses were conducted using SPSS statistical software (version 20.0; IBM SPSS, Armonk, NY, USA). The data are presented as the median and range. Categorical data were analyzed using a $\chi^{2}$ test or Fisher's exact test. The correlation between TopoII $\alpha$ and Ki67 expression was analyzed using Spearman's rank correlation test. Overall survival (OS) and recurrence-free survival (RFS) rates were evaluated by the Kaplan-Meier method, and the differences were examined with the log-rank test. Univariate risk ratios with $95 \%$ confidence intervals (CIs) were calculated using Cox proportional hazards regression models with enter-stepwise selection. To evaluate the prognostic value of TopoII $\alpha$ and Ki67 expression, a Cox multivariate proportional hazards regression analysis was performed with all the variables adopted for their prognostic significance by univariate analysis with enter-stepwise selection. $\mathrm{P}<0.05$ was considered to indicate a statistically significant difference.

\section{Results}

Demographic features and clinicopathological data. The present study cohort included 309 men and 44 women with a median age of 53 years (range, 13-81 years) and a median tumor size of $4 \mathrm{~cm}$ (range, $1-26 \mathrm{~cm}$ ). Serum AFP level was $\leq 400 \mu \mathrm{g} / \mathrm{l}$ in $66.0 \%$ of the patients and $>400 \mu \mathrm{g} / \mathrm{l}$ in $34.0 \%$ (normal ranges, $<20.0 \mathrm{ng} / \mathrm{ml}$ ) The tumors were well/moderately-differentiated in $93.2 \%$ of the patients and poorly-differentiated in $6.8 \%$; $26.1 \%$ of the tumors were on the left side and $73.9 \%$ were on the right side; and tumor TNM stage was I/II in $71.1 \%$ of the patients and IIIa in $28.9 \%$. 
Table I. Association between TopoII $\alpha /$ Ki67 expression and characteristics of patients $(\mathrm{n}=353)$.

\begin{tabular}{|c|c|c|c|c|c|c|}
\hline \multirow[b]{2}{*}{ Characteristic } & \multicolumn{2}{|c|}{ Ki67 expression } & \multirow[b]{2}{*}{ P-value } & \multicolumn{2}{|c|}{ TopoII $\alpha$ expression } & \multirow[b]{2}{*}{ P-value } \\
\hline & Low, n (\%) & High, n (\%) & & Low, n (\%) & High, n (\%) & \\
\hline Age & & & 0.427 & & & 0.218 \\
\hline$\leq 55$ years & $126(56.8)$ & $80(61.1)$ & & $127(55.9)$ & $79(62.7)$ & \\
\hline$>55$ years & $96(43.2)$ & $51(38.9)$ & & $100(44.1)$ & $47(37.3)$ & \\
\hline Gender & & & 0.373 & & & 0.921 \\
\hline Male & $197(88.7)$ & $112(85.5)$ & & $199(87.7)$ & $110(87.3)$ & \\
\hline Female & $25(11.3)$ & $19(14.5)$ & & $28(12.3)$ & $16(12.7)$ & \\
\hline Histological grade & & & 0.176 & & & 0.489 \\
\hline Well-/moderately-differentiated & $210(94.6)$ & $119(90.8)$ & & $210(92.5)$ & $119(94.4)$ & \\
\hline Poorly-differentiated & $12(5.4)$ & $12(9.2)$ & & $17(7.5)$ & $7(5.6)$ & \\
\hline Serum AFP level $(\mu \mathrm{g} / \mathrm{l})$ & & & 0.004 & & & 0.017 \\
\hline$\leq 400$ & 159 (71.6) & $74(56.5)$ & & $160(70.5)$ & $73(57.9)$ & \\
\hline$>400$ & $63(28.4)$ & $57(43.5)$ & & $67(29.5)$ & $53(42.1)$ & \\
\hline Tumor location & & & 0.641 & & & 0.641 \\
\hline Left & $56(25.2)$ & $36(27.5)$ & & $56(25.2)$ & $36(27.5)$ & \\
\hline Right & $166(74.8)$ & $95(72.5)$ & & $166(74.8)$ & $95(72.5)$ & \\
\hline TNM stage & & & 0.014 & & & 0.009 \\
\hline $\mathrm{I} / \mathrm{II}$ & $168(75.7)$ & $83(63.4)$ & & $172(75.8)$ & $79(62.7)$ & \\
\hline IIIa & $54(24.3)$ & $48(36.6)$ & & $55(24.2)$ & $47(37.3)$ & \\
\hline Survival & & & $<0.001$ & & & $<0.001$ \\
\hline Deceased & $72(32.4)$ & $81(61.8)$ & & $71(31.3)$ & $82(65.1)$ & \\
\hline Alive & $150(67.6)$ & $50(38.2)$ & & $156(68.7)$ & $44(34.9)$ & \\
\hline Tumor size & & & 0.014 & & & 0.001 \\
\hline$\leq 5 \mathrm{~cm}$ & $143(64.4)$ & $67(51.1)$ & & $150(66.1)$ & $60(47.6)$ & \\
\hline$>5 \mathrm{~cm}$ & 79 (35.6) & $64(48.9)$ & & 77 (33.9) & $66(52.4)$ & \\
\hline
\end{tabular}

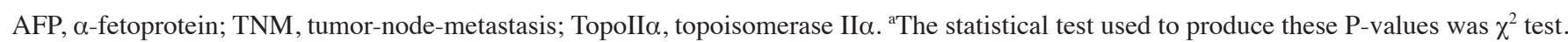

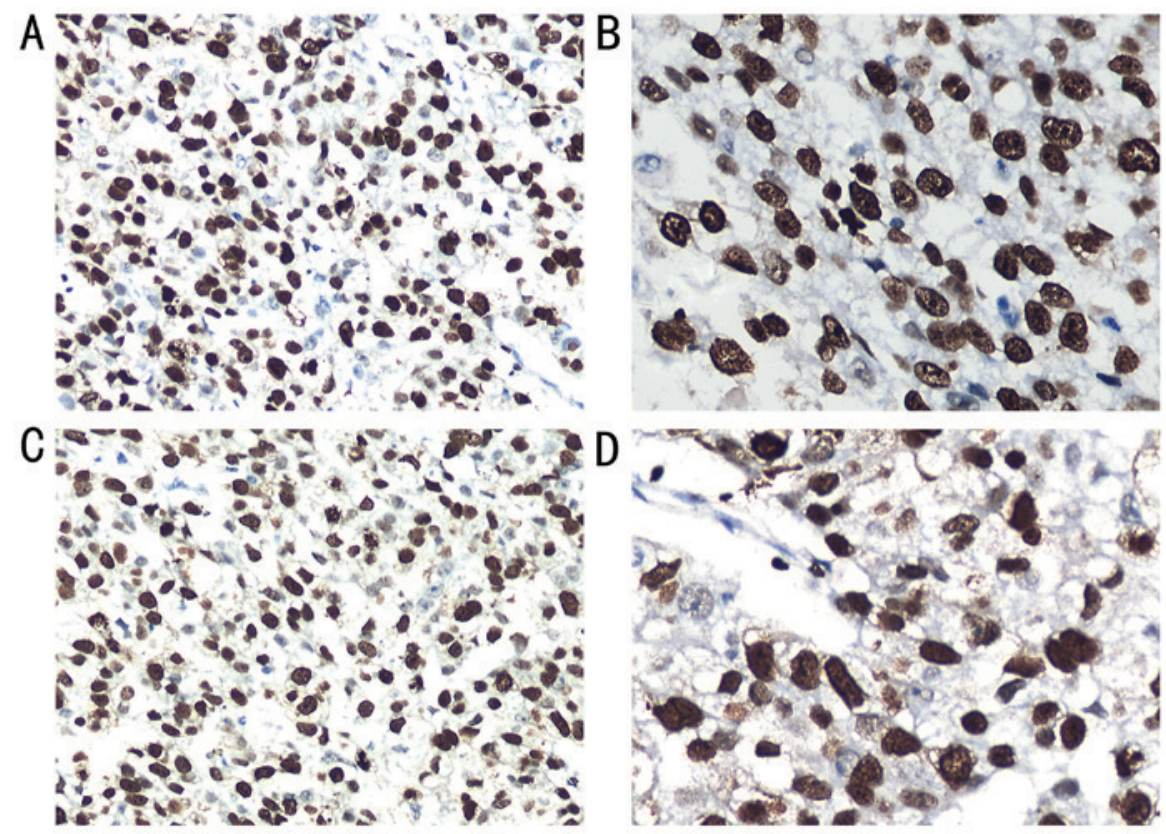

Figure 1. Observation of nuclear Ki67 staining in a case of HCC. (A) High expression of Ki67 in HCC (magnification, x200). (B) High expression of Ki67 in HCC (magnification, x400). Observation of nuclear TopoII $\alpha$ staining in a case of HCC. (C) High expression of TopoII $\alpha$ in HCC (magnification, x200). (D) High expression of TopoII $\alpha$ in HCC (magnification, x400). HCC, hepatocellular carcinoma; TopoII $\alpha$, topoisomerase II $\alpha$. 
Table II. Univariate and multivariate analysis of factors associated with overall survival.

\begin{tabular}{|c|c|c|c|c|}
\hline Characteristic & $\begin{array}{c}\text { Univariate analysis, } \\
\text { HR }(95 \% \mathrm{CI})\end{array}$ & P-value & $\begin{array}{c}\text { Multivariate analysis, } \\
\text { HR }(95 \% \mathrm{CI})\end{array}$ & P-value \\
\hline Age & & 0.322 & & \\
\hline$\leq 55$ years & 1 & & & \\
\hline$>55$ years & $0.848(0.612-1.175)$ & & & \\
\hline Gender & & 0.183 & & \\
\hline Male & 1 & & & \\
\hline Female & $0.688(0.397-1.193)$ & & & \\
\hline Histological grade & & 0.157 & & \\
\hline Well-/moderately-differentiated & 1 & & & \\
\hline Poorly-differentiated & $1.730(0.810-3.693)$ & & & \\
\hline Tumor location & & 0.822 & & \\
\hline Left & 1 & & & \\
\hline Right & $0.959(0.664-1.384)$ & & & \\
\hline Serum AFP level $(\mu \mathrm{g} / \mathrm{l})$ & & 0.284 & & \\
\hline$\leq 400$ & 1 & & & \\
\hline$>400$ & $1.198(0.861-1.558)$ & & & \\
\hline TNM stage & & $<0.001$ & & 0.599 \\
\hline $\mathrm{I} / \mathrm{II}$ & 1 & & 1 & \\
\hline IIIa & $2.265(1.638-3.131)$ & & $1.137(0.704-1.836)$ & \\
\hline Tumor size & & $<0.001$ & & 0.014 \\
\hline$\leq 5 \mathrm{~cm}$ & 1 & & 1 & \\
\hline$>5 \mathrm{~cm}$ & $2.472(1.794-3.406)$ & & $1.821(1.129-2.937)$ & \\
\hline Ki67 expression & & $<0.001$ & & \\
\hline Low & 1 & & & \\
\hline High & $2.892(2.093-3.995)$ & & & \\
\hline TopoII $\alpha$ expression & & $<0.001$ & & \\
\hline Low & 1 & & & \\
\hline High & $3.804(2.741-5.278)$ & & & \\
\hline TopoII $\alpha-$ Ki67expression & & $<0.001$ & & $<0.001$ \\
\hline TopoII $\alpha$ (low) or Ki67 (low) & 1 & & 1 & \\
\hline TopoII $\alpha$ (high) and Ki67 (high) & $4.264(3.030-6.000)$ & & $3.569(2.518-5.059)$ & \\
\hline
\end{tabular}

Univariate analysis, Cox proportional hazards regression model. Multivariate analysis, Cox proportional hazards regression model. Variables were adopted for their prognostic significance by univariate analysis with enter-stepwise selection $(\mathrm{P}<0.05)$. AFP, $\alpha$-fetoprotein; TNM, tumor-node-metastasis; TopoII $\alpha$, topoisomerase II $\alpha$; HR, hazard ratio; CI, confidence interval.

Ki67 expression and clinicopathological parameters of HCC are presented in Table I and Fig. 1. Ki67 expression was detected in the nuclei of the tumor cells in the HCC tissues (Fig. 1A and B). Among the 353 HCC tissues, 131 (37.1\%) exhibited high expression and $222(62.9 \%)$ had low expression levels. The results revealed that Ki67 expression was associated with TNM stage $(\mathrm{P}=0.014)$, tumor size $(\mathrm{P}=0.014)$ and high AFP level $(\mathrm{P}=0.004)$. However, no association was observed between Ki67 and age, sex, tumor location or histological grade.

TopoII $\alpha$ expression was also detected in the nuclei of the tumor cells in the HCC tissues (Table I; Fig. 1C and D). Of the 353 HCC tissues, 126 tissues (35.7\%) exhibited high expression and 227 (64.3\%) showed low expression. Similar to the expression pattern of Ki67, TopoII $\alpha$ was associated with TNM stage
$(\mathrm{P}=0.009)$, tumor size $(\mathrm{P}=0.001)$ and AFP level $(\mathrm{P}=0.017)$, whereas no association was observed between TopoII $\alpha$ and age, sex, tumor location or histological grade.

TopoII is associated with Ki67 expression in HCC. The IHC results revealed that TopoII $\alpha$ expression rate was positively correlated with Ki67 (Spearman's correlation coefficient, $\mathrm{r}=0.444 ; \mathrm{P}<0.001)$.

$R F S$. The results of the survival analyses are presented in Tables II and III and Fig. 2. In the present study, the 5-year RFS rate of the patients in the study cohort was $47.2 \%$. During the observation period, $171(48.4 \%)$ patients developed tumor recurrence. As predicted, a highly significant association was detected between tumor size (HR, 1.933; 95\% CI, 1.429-2.613; 
Table III. 5-year overall survival percentage according to clinicopathological variables.

\begin{tabular}{|c|c|c|c|}
\hline Characteristic & Cases, $n(n=353)$ & 5-year OS, \% & P-value \\
\hline Age & & & 0.319 \\
\hline$\leq 55$ years & 206 & 51.0 & \\
\hline$>55$ years & 147 & 54.1 & \\
\hline Sex & & & 0.178 \\
\hline Male & 309 & 51.4 & \\
\hline Female & 44 & 59.1 & \\
\hline TNM stage & & & $<0.001$ \\
\hline $\mathrm{I} / \mathrm{II}$ & 251 & 61.7 & \\
\hline IIIa & 102 & 29.3 & \\
\hline Tumor location & & & 0.821 \\
\hline Left & 92 & 59.0 & \\
\hline Right & 261 & 50.9 & \\
\hline Histological grade & & & 0.150 \\
\hline Well/moderately differentiated & 329 & 51.5 & \\
\hline Poorly differentiated & 24 & 63.1 & \\
\hline Serum AFP level $(\mu \mathrm{g} / \mathrm{l})$ & & & 0.281 \\
\hline$\leq 400$ & 233 & 53.7 & \\
\hline$>400$ & 120 & 49.8 & \\
\hline Tumor size & & & $<0.001$ \\
\hline$\leq 5 \mathrm{~cm}$ & 210 & 65.7 & \\
\hline$>5 \mathrm{~cm}$ & 143 & 33.5 & \\
\hline TopoII $\alpha$ expression & & & $<0.001$ \\
\hline Low & 227 & 66.5 & \\
\hline High & 126 & 23.8 & \\
\hline Ki67expression & & & $<0.001$ \\
\hline Low & 222 & 67.0 & \\
\hline High & 131 & 26.5 & \\
\hline TopoII $\alpha-$ Ki67 expression & & & $<0.001$ \\
\hline TopoII $\alpha$ (low) or Ki67 (low) & 270 & 61.9 & \\
\hline TopoII $\alpha$ (high) and Ki67 (high) & 83 & 18.2 & \\
\hline
\end{tabular}

P-value obtained using the Log-rank test. AFP, $\alpha$-fetoprotein; TNM, tumor-node-metastasis; OS, overall survival; TopoII $\alpha$, topoisomerase II $\alpha$.

$\mathrm{P}<0.001)$, TNM stage (HR, 2.843; 95\% CI, 2.088-3.871; $\mathrm{P}<0.001)$, TopoII $\alpha$ (HR, 2.320; 95\% CI, 1.708-3.151; $\mathrm{P}<0.001)$, Ki67 (HR, 1.760; 95\% CI, 1.297-2.389; P<0.001) and the development of tumor recurrence by the univariate analysis method. By multivariate analysis of all the factors that were significant in the univariate analysis, the independent prognostic indicators were TNM stage (HR, 3.757; 95\% CI, 2.033-6.945; $\mathrm{P}<0.001)$ and TopoII $\alpha$ (HR, 2.002; 95\% CI, 1.429-2.806; $\mathrm{P}<0.001)$. The TopoII $\alpha$-low group had a significantly increased RFS rate compared with the TopoII $\alpha$-high group (55.6 vs. $31.7 \%$; $\mathrm{P}<0.001)$.

$O S$. In the present study, the 5-year OS rate of the patients in the study cohort was $52.3 \%$. Univariate analysis revealed that tumor size (HR, 2.472; 95\% CI, 1.794-3.406), TNM stage (HR, 2.625; 95\% CI, 1.638-3.131), TopoIIa (HR, 3.804; 95\% CI, 2.741-5.278) and Ki67 (HR, 2.829; 95\% CI,
2.093-3.995) were poor predictors for OS, while age, sex, histological grade, tumor location and serum AFP level had no prognostic significance for OS. Multivariate analyses of factors demonstrated that the TNM stage (HR, 3.757; 95\% CI, 2.033-6.945), TopoII $\alpha$ (HR, 2.749; 95\% CI, 1.919-3.939), tumor size (HR, 1.938; 95\% CI, 1.203-3.124) and Ki67 (HR, 1.816; 95\% CI, 1.273-2.589) were the independent prognostic indicators. The TopoII $\alpha$-low group had a significantly increased OS rate compared with the TopoII $\alpha$-high group (66.5 vs. $23.8 \%$; $\mathrm{P}<0.001)$. The OS rate was also significantly increased in the Ki67-low group compared with in the Ki67-high group (67.0 vs. $26.5 \%$; $\mathrm{P}<0.001)$.

\section{Discussion}

$\mathrm{HCC}$ is a common malignant tumor with a high mortality rate in humans $(20,21)$. Due to the vast heterogeneity of patients 
with HCC, prognosis following surgery may differ, and current clinicopathological factors, including AFP, TNM stage and tumor size, are not able to accurately predict the outcomes of all patients with HCC (22). Thus, there is an urgent requirement to find new biomarkers for prognosis and therapeutic HCC targets.

The proliferation status of tumor cells is an important parameter that reflects the biological characteristics of the tumor, affects prognosis and the efficiency of treating the tumor directly (16). TopoII $\alpha$ and Ki67 are markers of cell proliferation in normal and neoplastic tissues; their expression levels may be used as a predictive parameter $(9,16)$.

It is established that Ki67 protein is a traditional proliferation marker, and various studies have explored the predictive value of the Ki67-labeling index (17,23-27). The associations between Ki-67 and clinicopathological features, as well as its prognostic significance in numerous cancer types, including breast cancer, pituitary adenomas, laryngeal carcinoma, adrenocortical carcinoma, ovarian carcinoma and lymphoma, have been investigated, and the results were similar (17,23-27). These previous studies demonstrated that the expression of the Ki67 protein was associated with a more advanced tumor stage, underlining the importance of $\mathrm{Ki}-67$ as a prognostic parameter.

A meta-analysis of 54 studies with a total of 4,996 patients examined the effect of high Ki67 on HCC clinicopathological features and patient DFS, RFS and OS (28). The results revealed that a high Ki67 level was significantly associated with advanced HCC stage, which included poor differentiation, large tumors and an increased number of tumor nodes, with metastasis, cirrhosis and vein invasion In accordance with previous studies, the present study demonstrated that Ki67 expression is associated with TNM stage, tumor size and AFP level. Using multivariate analysis, Ki-67 was an independent factor for OS, but was not associated with RFS. In addition, the OS rate was increased in the Ki67-low group compared with the Ki67-high group, which may indicate that a high expression level of Ki67 is associated with poor prognosis in patients with HCC.

Similar to Ki67, TopoII $\alpha$ is another proliferation marker that is considered to function in growth-dependent processes, including DNA replication and chromosome segregation, due to its ability to break the DNA double helix. TopoII $\alpha$ is involved in the DNA replication process and chromosome segregation, which are crucial for cell growth and development $(11,9)$ and may facilitate tumor cell growth $(29,30)$. Enzyme concentrations are upregulated dramatically during periods of cell proliferation, and they are associated with the proliferation of the cells $(31,32)$. The prognostic value of TopoII $\alpha$ has been pointed out by different researchers in various types of cancer (33).

While studying patients with HCC, Wong et al (34) identified that TopoII $\alpha$ expression was associated with advanced histological grading, microvascular invasion and early age onset of the malignancy, and that high TopoII $\alpha$ protein score (Grade 3) was associated with non-responsiveness to chemotherapy and early disease-associated mortalities. Similar to their study, the present study revealed that TopoII $\alpha$ may be detected in the nuclei of tumor cells in HCC tissues. Of the 353 HCC tissues in the present study, 126 (35.7\%) displayed high
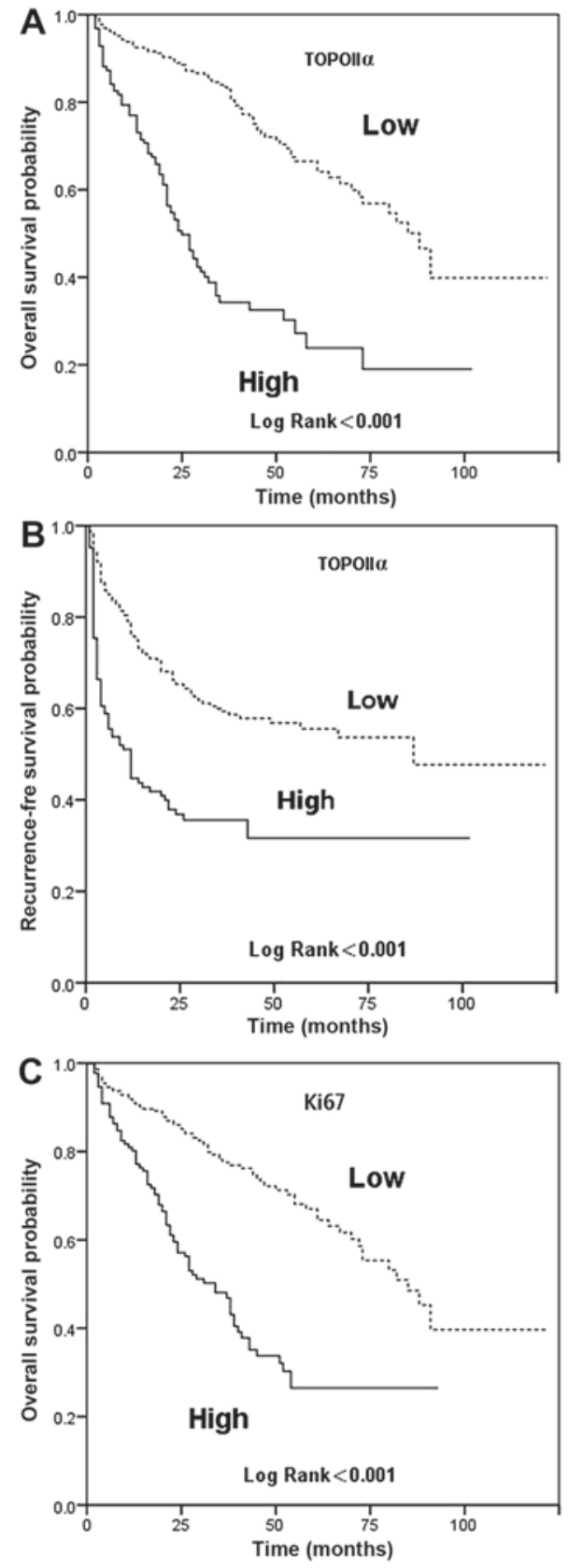

Figure 2. Kaplan-Meier survival curves demonstrating (A) decreased overall survival and (B) recurrence-free survival in the TopoII $\alpha$-high group, and (C) decreased overall survival in the Ki67-high group. TopoII $\alpha$, topoisomerase II $\alpha$.

expression. In addition, TopoII $\alpha$ was associated with TNM stage, tumor size and high AFP level. By multivariate analysis, TopoII $\alpha$ remained an independent factor for OS and RFS. In addition, the low-TopoII $\alpha$ group had increased OS and RFS rates compared with the high-TopoII $\alpha$ group.

In 2001, Watanuki et al (35) reported an association between the TopoII $\alpha$ index and the Ki-67 index in 70 resected HCC samples, and patients with lower TopoII $\alpha$ had prolonged DFS and OS times. Most recently, the prognostic significance of TopoII $\alpha$ in HCC was further elucidated by Panvichian et al (36), who studied gene aberrations of TopoII $\alpha$ and protein expression levels of TopoII $\alpha$ and $\mathrm{Ki}-67$ in tumor and corresponding non-tumor tissues. The overexpression of 
TopoII $\alpha$ was only identified in tumor tissues; TopoII $\alpha$ gene amplification was not detected in tumor or non-tumor tissues, and overexpression of TopoII $\alpha$ was associated with Ki-67. Based on previous studies, the present study investigated whether TopoII $\alpha$ expression in HCC is associated with the expression of other, more established markers of proliferation (such as Ki67). Notably, the present study revealed that TopoII $\alpha$ expression rate is positively associated with $\mathrm{Ki67}$, and the presence of TopoII $\alpha$ predicted reduced RFS, which is in accordance with earlier work by Watanuki et al (35).

The present study was limited by its retrospective nature, and all the patients in the present cohort were confined by the inclusion criteria. As the number of poorly differentiated tumors in the present study was small, additional research with a larger sample of HCC cases from different centers may be of great value.

In conclusion, TopoII $\alpha$ and $\mathrm{Ki} 67$ may serve as an unfavorable prognostic factor for patients with HCC undergoing curative tumor resection. Examination of TopoII $\alpha$ and Ki67 may help to stratify subgroups of patients and establish targeted therapies. Thus, undertaking adjuvant treatment early in Ki67 (high) or TopoII $\alpha$ (high) patients following surgery may prolong survival. However, the underlying mechanism requires additional study.

\section{Acknowledgements}

The authors would like to thank Professor Yu Yinghao for his technical support in experiments. The present study was jointly supported by grants from the Key project of Natural Science Foundation of Fujian Province (grant no. 2014Y0034) and the Innovation Team Foundation of Fuzhou General Hospital (grant no. 2015 Y0026).

\section{References}

1. Kew MC: Hepatocellular carcinoma: Epidemiology and risk factors. J Hepatocell Carcinoma 1: 115-125, 2014.

2. Torre LA, Bray F, Siegel RL, Ferlay J, Lortet-Tieulent J and Jemal A: Global cancer statistics, 2012. CA Cancer J Clin 65: 87-108, 2015

3. Tanaka S and Arii S: Molecular targeted therapies in hepatocellular carcinoma. Semin Oncol 39: 486-492, 2012.

4. Olsen SK, Brown RS and Siegel AB: Hepatocellular carcinoma: Review of current treatment with a focus on targeted molecular therapies. Therap Adv Gastroenterol 3: 55-66, 2010.

5. Furihata T, Sawada T, Kita J, Iso Y, Kato M, Rokkaku K, Shimoda M and Kubota K: Serum alpha-fetoprotein level per tumor volume reflects prognosis in patients with hepatocellular carcinoma after curative hepatectomy. Hepatogastroenterology 55: 1705-1709, 2008

6. Bhattacharya S, Steele R, Shrivastava S, Chakraborty S, Di Bisceglie AM and Ray RB: Serum miR-30e and miR-223 as novel noninvasive biomarkers for hepatocellular carcinoma. Am J Pathol 186: 242-247, 2016.

7. Cubeddu A, Astara G, Madeddu C, Ruggiero V, Cabula C, Serra G, Ganga R, Faloppi L, Cascinu S and Scartozzi M: L47Osteopontin (OPN) and interleukin-6 (IL-6) as predictive biomarkers in HCC receiving loco-regional treatment: Preliminary results. Ann Oncol 26 (Suppl 6): vi.124-vi, 2015.

8. Xu B, Cai Z, Zeng Y, Chen L, Du X, Huang A, Liu X and Liu J: $\alpha$-Methylacyl-CoA racemase (AMACR) serves as a prognostic biomarker for the early recurrence/metastasis of HCC. J Clin Pathol 67: 974-979, 2014

9. Watt PM and Hickson ID: Structure and function of type II DNA topoisomerases. Biochem J 303: 681-695, 1994.

10. Forterre P, Gribaldo S, Gadelle D and Serre MC: Origin and evolution of DNA topoisomerases. Biochimie 89: 427-446, 2007.
11. McClendon AK and Osheroff N: DNA topoisomerase II, genotoxicity, and cancer. Mutat Res 623: 83-97, 2007.

12. Xu XL, Zheng WH, Fu ZX, Li ZP, Xie HX, Li XX, Jiang LH, Wang Y, Zhu SM and Mao WM: Topo2A as a prognostic biomarker for patients with resectable esophageal squamous cell carcinomas. Med Oncol 32: 396, 2015.

13. Parker AS, Eckel-Passow JE, Serie D, Hilton T, Parasramka M, Joseph RW, Wu KJ, Cheville JC and Leibovich BC: Increased expression of topoisomerase II alpha is an independent marker of increased risk of cancer-specific death in patients with clear cell renal cell carcinoma. Eur Urol 66: 929-935, 2014.

14. Mrklić I, Pogorelić Z, Ćapkun V and Tomić S: Expression of topoisomerase II- $\alpha$ in triple negative breast cancer. Appl Immunohistochem Mol Morphol 22: 182-187, 2014

15. Lan J, Huang HY, Lee SW, Chen TJ, Tai HC, Hsu HP, Chang KY and Li CF: TOP2A overexpression as a poor prognostic factor in patients with nasopharyngeal carcinoma. Tumour Biol 35: 179-187, 2014.

16. Scholzen T and Gerdes J: The Ki-67 protein: From the known and the unknown. J Cell Physiol 182: 311-322, 2000.

17. Mahmoud AM, Macias V, Al-alem U, Kresovich JK, Khramtsova G, Kajdacsy-Balla A, Wiley EL and Rauscher GH: $\mathrm{Ki} 67$ is an independent prognostic marker in breast cancer even after accounting for molecular subtype. Cancer Res 74: 5569, 2014.

18. Kee KM, Wang JH, Lee CM, Chen CL, Changchien CS, Hu TH, Cheng YF, Hsu HC, Wang CC, Chen TY, et al: Validation of clinical AJCC/UICC TNM staging system for hepatocellular carcinoma: Analysis of 5,613 cases from a medical center in southern Taiwan. Int J Cancer 120: 2650-2655, 2007.

19. Schmilovitz-Weiss H, Tobar A, Halpern M, Levy I, Shabtai E and Ben-Ari Z: Tissue expression of squamous cellular carcinoma antigen and Ki67 in hepatocellular carcinoma-correlation with prognosis: A historical prospective study. Diagn Pathol 6: 121, 2011.

20. Li WQ, Park Y, McGlynn KA, Hollenbeck AR, Taylor PR, Goldstein AM and Freedman ND: Index-based dietary patterns and risk of incident hepatocellular carcinoma and mortality from chronic liver disease in a prospective study. Hepatology 60: 588-597, 2014.

21. El-Serag HB: Hepatocellular carcinoma. N Engl J Med 365: 1118-1127, 2011.

22. Qin LX and Tang ZY: Recent progress in predictive biomarkers for metastatic recurrence of human hepatocellular carcinoma: A review of the literature. J Cancer Res Clin Oncol 130: 497-513, 2004.

23. Chiloiro S, Bianchi A, Doglietto F, de Waure C, Giampietro A, Fusco A, Iacovazzo D, Tartaglione L, Di Nardo F, Signorelli F, et al: Radically resected pituitary adenomas: Prognostic role of Ki 67 labeling index in a monocentric retrospective series and literature review. Pituitary 17: 267-276, 2014.

24. Rademakers SE, Hoogsteen IJ, Rijken PF, Terhaard CH, Doornaert PA, Langendijk JA, van den Ende P, van der Kogel AJ, Bussink J and Kaanders JH: Prognostic value of the proliferation marker Ki-67 in laryngeal carcinoma: Results of the accelerated radiotherapy with carbogen breathing and nicotinamide phase III randomized trial. Head Neck 37: 171-176, 2015.

25. Beuschlein F, Weigel J, Saeger W, Kroiss M, Wild V, Daffara F, Libé R, Ardito A, Al Ghuzlan A, Quinkler M, et al: Major prognostic role of $\mathrm{Ki} 67$ in localized adrenocortical carcinoma after complete resection. J Clin Endocrinol Metab 100: 841-849, 2015.

26. Battista MJ, Mantai N, Sicking I, Cotarelo C, Weyer V, Lebrecht A, Solbach C and Schmidt M: Ki-67 as an independent prognostic factor in an unselected cohort of patients with ovarian cancer: Results of an explorative, retrospective study. Oncol Rep 31: 2213-2219, 2014.

27. He X, Chen Z, Fu T, Jin X, Yu T, Liang Y, Zhao X and Huang L: $\mathrm{Ki}-67$ is a valuable prognostic predictor of lymphoma but its utility varies in lymphoma subtypes: Evidence from a systematic meta-analysis. BMC Cancer 14: 153, 2014.

28. Luo Y, Ren F, Liu Y, Shi Z, Tan Z, Xiong H, Dang Y and Chen G: Clinicopathological and prognostic significance of high Ki-67 labeling index in hepatocellular carcinoma patients: A meta-analysis. Int J Clin Exp Med 8: 10235-10247, 2015.

29. Coss A, Tosetto M, Fox EJ, Sapetto-Rebow B, Gorman S, Kennedy BN, Lloyd AT, Hyland JM, O'Donoghue DP, Sheahan K, et al: Increased topoisomerase IIalpha expression in colorectal cancer is associated with advanced disease and chemotherapeutic resistance via inhibition of apoptosis. Cancer Lett 276: 228-238, 2009. 
30. Bidgoli SA, Azizi E and Zavarhei MD: Association between p53 expression and Bcl-2, P-glycoprotein, topoisomerase II alpha, thymidylate synthase and thymidine phosphorylase as potential therapeutic targets in colorectal cancer patients. Pak J Biol Sci 10: 3350-3355, 2007.

31. Shvero J, Koren R, Shvili I, Yaniv E, Sadov R and Hadar T: Expression of human DNA topoisomerase II-alpha in squamous cell carcinoma of the larynx and its correlation with clinicopathologic variables. Am J Clin Pathol 130: 934-849, 2008.

32. Kim EJ, Lee YS, Kim YJ, Kim MJ, Ha YS, Jeong P, Lee OJ and Kim WJ: Clinical implications and prognostic values of topoisomerase-II alpha expression in primary non-muscle-invasive bladder cancer. Urology 75: 1516.e9-e13, 2010.

33. Ali Y and Abd Hamid S: Human topoisomerase II alpha as a prognostic biomarker in cancer chemotherapy. Tumour Biol 37 $47-55,2016$
34. Wong N, Yeo W, Wong WL, Wong NL, Chan KY, Mo FK, Koh J, Chan SL, Chan AT, Lai PB, et al: TOP2A overexpression in hepatocellular carcinoma correlates with early age onset, shorter patients survival and chemoresistance. Int J Cancer 124: 644-652, 2009

35. Watanuki A, Ohwada S, Fukusato T, Makita F, Yamada T, Kikuchi A and Morishita Y: Prognostic significance of DNA topoisomerase IIalpha expression in human hepatocellular carcinoma. Anticancer Res 22: 1113-1119, 2002.

36. Panvichian R, Tantiwetrueangdet A, Angkathunyakul $\mathrm{N}$ and Leelaudomlipi S: TOP2A amplification and overexpression in hepatocellular carcinoma tissues. Biomed Res Int 2015: 381602, 2015. 